\title{
EFFECTS OF POLYBROMINATED DIPHENYL ETHERS ON THYROID HORMONE, NEURODEVELOPMENT AND FERTILITY IN RODENTS AND HUMANS
}

\author{
MARTA CZERSKA, MAREK ZIELIŃSKI, JOANNA KAMIŃSKA, and DANUTA LIGOCKA
}

Nofer Institute of Occupational Medicine, Łódź, Poland

Department of Toxicology and Carcinogenesis

\begin{abstract}
Polybrominated diphenyl ethers (PBDEs) are used as flame retardants. Due to their widespread use in many consumer products, PBDEs can be found in food as well as in the environment. Their presence has also been found in the human serum, human adipose tissue and human breast milk. Results of experimental studies suggest that the presence of PBDE in the environment is not neutral to our health. In rats and mice exposed to PBDE disturbances in thyroid hormone homeostasis and reproductive system such as changes in reproductive organs weight and disorders in sperm motility and motion were found. In rodents, pre- and postnatal exposure to PBDE can cause neurobehavioral effects. Also in humans disturbances in thyroid hormone system, weight of reproductive organs and concentrations of sex hormones associated with PBDEs serum concentrations were found. Exposure to PBDEs during pregnancy may lead to slower mental and psychomotor development in infants. In this paper the results of previous animal and human studies are reviewed.
\end{abstract}

Key words:

PBDEs, Thyroid hormone, Neurodevelopment, Fertility, Rodents, Humans

\section{INTRODUCTION}

Polybrominated diphenyl ethers (PBDEs) are compounds characterized by a high flash point, that is why they are widely used as flame retardants - they protect against inflammation, slow down the process of smoking and reduce the spread of fire. The use of flame retardants is essential to reduce the damage caused by fires and to reduce the risk to human life [1]. PBDEs are used in plastics, paints, synthetic textiles, car and furniture upholstery, as well as in TV sets and computers [2]. There are three types of commercial mixtures of PBDEs, named after the dominant congeners: pentaBDE, octaBDE and decaBDE [3].
Under the Directive of European Parliament, since 2004, pentaBDE and octaBDE have no longer been produced in Europe [4]. Components of commercial pentaBDE (tetrabromodiphenyl ether and pentabromodiphenyl ether) and components of commercial octaBDE (hexabromodiphenyl ether and heptabromodiphenyl ether) in 2010 were included in Annex A of the Stockholm Convention [5]. A mixture of decaBDE is currently used by production of electrical and electronic equipment, wires, cables, pipes and in the textile industry.

The theoretical number of possible congeners of PBDEs is 209; they differ in number and place of bromine substitution

This study was performed under the project: IMP 4.12: Assessment of environmental exposure to polybrominated biphenyls (PBB), polybrominated dioxins (PBDD) and polybrominated furans (PBDF) - development and validation of the HRGC/HRMS method. Manager of the project: Danuta Ligocka, PhD.

Received: January 24, 2013. Accepted: September 4, 2013.

Corresponding author: M. Czerska, Department of Toxicology and Carcinogenesis, Nofer Institute of Occupational Medicine, św. Teresy 8, 91-348 Łódź, Poland (e-mail: m-czerska@wp.pl). 
in the molecule [6]. PBDEs are not chemically bound to the polymers; therefore, they can leak into the environment [7]. They are lipophilic and bioaccumulative in wildlife and humans, and they undergo biomagnification, i.e. move up in the food chain [6]. Furthermore, PBDEs are characterized by high durability and resistance to physical, chemical and biological degradation [8]. They have been found in household dust, food, human breast milk, human adipose tissue and human serum [2]. Experimental studies show it is a group of compounds that require particular interest due to their possible negative impact on the human health and environment [9].

The most frequently investigated congeners are: BDE-209, BDE-47, BDE-100, BDE-153, BDE-154, BDE-183 and BDE-99 since they are the most abundant congeners in food, household dust, human serum, human adipose tissue and human milk [2].

Research on the effects of PBDEs on living organisms has been conducted in vitro and in vivo primarily in mice, rats and minks [2]. Endocrine disorders constitute the main effect of PBDEs. Polybrominated diphenyl ethers are classified as endocrine disruptors, compounds that interfere with synthesis, secretion, transport, binding, operation and elimination of hormones responsible for the development, preservation, and maintenance of fertility homeostasis [10]. Many works have been dedicated to the study of the impact of PBDEs on thyroid hormones, neurodevelopment, reproductive organs and fertility in laboratory animals. However, the number of papers connected with PBDEs influence on human health is limited.

\section{THYROID HORMONES}

\section{Animal studies}

The thyroid gland is the largest endocrine gland. Secretion of thyroxine (T4) and triiodothyronine (T3) is under regulation of pituitary hormone thyrotropin (thyroid-stimulating hormone, TSH) which is controlled by TSH-releasing hormone (TRH) secreted by the hypothalamus. T3 and T4 are very important in development as they regulate growth and correct maturation of the brain [11].

Kuriyama et al. [12] treated pregnant Wistar Rats by gavage with a single dose of 0.06 or $0.3 \mathrm{mg}$ BDE-99/kg b.w. (99.98\% purity) on gestational day (GD) 6. In the dams exposed to BDE-99, concentration of total T4 was significantly lower compared to the control. Serum total T3 concentrations were reduced in $0,06 \mathrm{mg} / \mathrm{kg}$ b.w. group. Female pups exposed prenatally to $0,06 \mathrm{mg} / \mathrm{kg}$ b.w. of BDE-99 displayed lower free thyroxine (FT4) concentration on postnatal day (PND) 1 compared to the controls. On PND 22, serum total T4 concentration was lower in male and female offspring while FT4 was lower only in female pups [12]. CD-1 pregnant mice were treated daily by gavage with 10,500 or $1500 \mathrm{mg}$ BDE-209/kg b.w. (98\% purity) from GD 0 till GD 17 [13].

On PND 71, blood samples were collected and the male pups were killed. Serum total T3 levels decreased significantly in the lower and the higher dose groups $(10 \mathrm{mg} /$ $\mathrm{kg}$ and $1500 \mathrm{mg} / \mathrm{kg}$, respectively), which the authors explained as possibly inverted U-shaped curve trend. There were no significant changes in total T4 levels in any of the treatment groups [13].

In female Sprague-Dawley rats exposed daily to BDE-47 (>98\% purity) at $18 \mathrm{mg} / \mathrm{kg}$ b.w. for 14 days, serum free T4 levels were significantly lower. The TSH serum levels did not change significantly [14]. Andrade et al. [15] treated pregnant Wistar rats by gavage with a single dose of BDE-47 (0.14 or $0.7 \mathrm{mg} / \mathrm{kg}$ b.w.) on GD 6. The pups were killed on PND 1, PND 14 and PND 22. Significant reduction was observed in TSH levels in $0.14 \mathrm{mg} / \mathrm{kg}$ b.w. group on PND 14 and PND 22, and in T3 concentrations in the same group on PND 14. In the $0.7 \mathrm{mg} / \mathrm{kg}$ b.w. group, a significant reduction in T3 levels was observed on PND 1 and PND 14 and an increase in T4 concentration on PND 22. No changes were observed in free triodothyronine (FT3) and TSH levels in $0.7 \mathrm{mg} / \mathrm{kg}$ b.w. group [15]. 
Table 1. Summary of PBDEs effect on thyroid hormone

\begin{tabular}{|c|c|c|c|c|c|}
\hline Congener & Species & $\begin{array}{c}\text { Gestational } \\
\text { or postnatal day }\end{array}$ & Exposure level & PBDEs effect & Reference \\
\hline $\begin{array}{l}\text { BDE-99 } \\
\text { (99,8\% purity) }\end{array}$ & Wistar rats & GD 6 & $\begin{array}{l}0.06 \text { or } 0.3 \mathrm{mg} / \mathrm{kg} \text { b.w. } \\
\text { by gavage }\end{array}$ & $\begin{array}{l}\text { lower T4 levels in exposed dams } \\
\text { lower T4 levels in male and female } \\
\text { offspring on PND } 22 \\
\text { lower FT4 levels in female on PND } 1 \\
\text { (0.06 mg/kg b.w.) } \\
\text { lower FT4 levels in exposed female } \\
\text { offspring on PND } 22 \\
\text { lower T3 levels in dams ( } 0.06 \mathrm{mg} / \mathrm{kg} \text { b.w.) }\end{array}$ & [12] \\
\hline $\begin{array}{l}\text { BDE-209 } \\
\text { (98\% purity) }\end{array}$ & CD-1 mice & GD 0-GD 17 & $\begin{array}{l}10,500 \\
\text { or } 1500 \mathrm{mg} / \mathrm{kg} \text { b.w. } \\
\text { by gavage }\end{array}$ & $\begin{array}{l}\text { no changes observed in T4 levels } \\
\text { lower T3 levels in } 10 \text { and } 1500 \mathrm{mg} / \mathrm{kg} \text { b.w. } \\
\text { group }\end{array}$ & [13] \\
\hline $\begin{array}{l}\text { BDE-47 } \\
\text { ( } 98 \% \text { purity) }\end{array}$ & $\begin{array}{l}\text { Sprague- } \\
\text { Dawley rats }\end{array}$ & $\begin{array}{l}\text { Postnatal, } \\
14 \text { days }\end{array}$ & $\begin{array}{l}6 \text { and } 18 \mathrm{mg} / \mathrm{kg} \text { b.w. } \\
\text { by gavage }\end{array}$ & lower FT4 in $18 \mathrm{mg} / \mathrm{kg}$ b.w. group & [14] \\
\hline BDE-47 & Wistar rats & GD 6 & 0.14 or $0.7 \mathrm{mg} / \mathrm{kg}$ b.w. & $\begin{array}{l}\text { higher T4 levels in } 0.7 \mathrm{mg} / \mathrm{kg} \text { b.w. group } \\
\text { on PND } 22 \\
\text { no changes observed in FT4 levels } \\
\text { lower T3 levels in } 0.7 \mathrm{mg} / \mathrm{kg} \text { b.w. group on } \\
\text { PND } 1 \\
\text { lower T3 levels in } 0.14 \text { and } 0.7 \mathrm{mg} / \mathrm{kg} \text { b.w. } \\
\text { group on PND } 14 \\
\text { no change in FT3 levels } 0.7 \mathrm{mg} / \mathrm{kg} \text { b.w. } \\
\text { group } \\
\text { lower TSH levels in } 0.14 \mathrm{mg} / \mathrm{kg} \text { b.w. group } \\
\text { on PND } 14,22 \\
\text { no change in TSH levels } 0.7 \mathrm{mg} / \mathrm{kg} \text { b.w. } \\
\text { group }\end{array}$ & {$[15]$} \\
\hline $\begin{array}{l}\text { BDE-209 } \\
\text { (98,5\% purity) }\end{array}$ & C57BL6/J mice & PND 2- PND 15 & 6 or $20 \mathrm{mg} / \mathrm{kg}$ b.w. orally & lower T4 levels in exposed animals & {$[17]$} \\
\hline
\end{tabular}

Darnued and Sinjari [16] received similar results. They observed a negative relationship between PBDEs concentration and T4 levels in rats and mice while the TSH concentrations were generally not affected.

Also Rice et al. [17] observed a decrease in serum T4 levels in C57BL6/J male mice postnatally exposed to a daily oral dose of 6 or $20 \mathrm{mg} / \mathrm{kg}$ b.w. BDE-209 (99.5\% purity) from PND 2 till PND 15.

The results of the work on the effects of PBDEs on thyroid hormones are summarized in Table 1.

In summary, endocrine system seems to be the main target of PBDEs. Exposure of rats and mice during gestation leads to hormonal disorders in their offspring $[12,13,15]$, whereas exposure of pups leads to hormonal disorders in their bodies [17]. FT3 levels in pups can be decreased both, after single gestational administration [12,15] and chronic gestational administration [13]. Disorders in T4 levels can be a result of gestational exposure to BDE-99 [12] and BDE-47 [15] administered at a single dose. PBDEs can also affect levels of FT4, T3and TSH $[12,15]$.

\section{Human studies}

Previous works in the field of thyroid hormone focus on the analysis of the relationship between serum levels of PBDEs in the study population and the concentration of T4, FT4, T3, FT3 and TSH. 
Chevrier et al. [18] measured the concentration of selected PBDE congeners, FT4, T4 and TSH in 270 pregnant women in order to determine whether PBDEs serum concentration is associated with $\mathrm{TH}$ levels.

In serum samples, BDE-47 accounted for more than a half of total PBDEs, and it was followed by BDE-99, BDE-153 and BDE-100 [18].

There was no association between PBDE serum levels and T4 or FT4 serum concentration, but all PBDE congeners were significantly inversely associated with TSH. The state of reduced levels of serum TSH with normal FT4 values is defined as subclinical hyperthyroidism [19]. The results of the reported research suggest that PBDEs may display a hyperthyroid effect [18].

Although it is likely that subclinical hyperthyroidism may cause long-term consequences [20,21] it is not associated with adverse pregnancy outcomes [19].

Lin et al. [22] analyzed the relationship between PBDEs levels in breast milk and levels of thyroid hormones in maternal and cord blood.

It was found that BDE-47 and BDE-28 were negatively correlated with transthyretin level in maternal blood. BDE-99 had a negative correlation with thyroxine binding protein (TBG) in cord blood. Higher levels of BDE-196, BDE-197 and BDE-207 were positively associated with FT4 in cord blood. Those authors suggest that this may result from probable ability of PBDEs to bind receptors of TBG and thus induce secretion of FT4 into cord blood [22].

In humans, PBDEs exposure can lead to disturbances in thyroid hormones. Congeners like BDE-47, BDE-28 are negatively correlated with transthyretin serum concentration. PBDEs can also reduce serum TSH concentration, which with normal FT4 level is defined as subclinical hyperthyroidism [19]. It is suggested that PBDEs may display a hyperthyroid effect [18]. It seems likely that subclinical hyperthyroidism may cause long-term consequences such as osteoporosis, cardiovascular morbidity and progression to overt thyrotoxicosis or thyroid failure [20,21].

\section{NEURODEVELOPMENT}

\section{Animal studies}

Neurodevelopmental effect of exposure to PBDEs is tested by giving rodents different doses of PBDE congeners during brain growth spurt (BGS). BGS is the period during which brain development is characterized by a series of rapid fundamental developmental changes [23]. It is the time when animals acquire new motor and sensory abilities [24], and the synthesis of brain lipids reaches maximum [7]. In rodents, BGS takes place during neonatal period with peak time around PND 10 and ends around 3rd-4th week of life [7].

Eriksson et al. [25,26] and Viberg et al. [27] investigated the influence of PBDEs on spontaneous behavior, learning and memory functions in mice. Eriksson et al. [25] found out that neonatal exposure to BDE-99 and BDE-47 (>98\% purity) may result in permanent aberrations of spontaneous behavior in NMRI mice. Neonatal exposure to BDE-99 also damages the ability to learn and memorize [25]. BDE-99-treated NMRI mice in neonatal period (on PND 3 and PND 10) showed significant differences in spontaneous behavior, while mice neonatally exposed to BDE-99 on PND 19 showed no changes in spontaneous behavior [26].

NMRI mice neonatally exposed to BDE-203 (>98\% purity) on PND 3 and PND 10, and to BDE-206 (>98\% purity) on PND 10 demonstrated significant differences in spontaneous behavior, while mice neonatally exposed to PBDE 206 on PND 3 showed no significant differences in this area [27]. The results for mice neonatally exposed to BDE-183 (98\% purity) differed depending on the exposure day: there were no significant differences in spontaneous behavior of mice treated with BDE-183 on PND 10, while mice treated with BDE-183 on PND 3 showed disturbances in spontaneous behavior [27].

All the disturbances (in spontaneous behavior, learning and memorizing) appeared if mice were treated with PBDEs during the period of rapid brain growth [26]. 
The scientific research indicates differences in neurotoxicity among different PBDE congeners [25] and it suggests that there may be differences in uptake and/or metabolism between the individual PBDE congeners [27].

Viberg et al. [7] treated young NMRI mice with BDE-209 during BGS. 10-day old mice received 1.34, 13.4 or $20.1 \mathrm{mg} \mathrm{BDE}-209 / \mathrm{kg}$ b.w., 3-day old mice and 19-day old mice were given 2.22 or $20.1 \mathrm{mg}$ BDE-209/kg b.w. It was a single oral dose administered via a metal gastric tube. When mice were 2, 4 and 6 months old, spontaneous behavior tests were performed.

In mice treated with BDE-209 on PND 3, there was a dose-related change in locomotion, rearing and total activity at the 2nd month of life. The changes in behavior were observed also in the 4th and 6th month of age [7].

Viberg et al. [28] treated 10-day old C57/B1 male and female mice pups with 0.4, 0.8, 4, 8, 16 mg BDE-99/kg b.w. (>99\% purity) via metal gastric tube as one single dose. Male and female mice were tested in spontaneous behavior test when they were at the age of 2,5 and 8 months.

Perinatal exposure to low doses of BDE-99 resulted in dose- and time-response-related disturbances in the spontaneous behavior of adult male and female C57/B1 mice. The study shows that these disturbances get more severe with age [28].

Branchi et al. [29] treated CD-1 mice pups with 0.6, 6 or 30 mg BDE-99/kg b.w. from GD 6 till PND 21. Pups were weaned at PND 21 and four females and four males from the litter were used for neurobehavioral tests: assessment of somatic and neurobehavioral development, ultrasonic vocalizations, homing test and open field test.

There were no differences in ultrasonic vocalization in any of the treatment groups. No significant differences were also observed in homing test in treatment groups compared to the controls [29].

There were some differences in BDE-99 treated mice behavior and activity in open-field test compared to the controls. Locomotor activity was affected on PND 34,
PND 60 and PND 120. On PND 34, the mice exposed to medium dose were hyperactive just as the mice from low and medium dose groups on PND 60. The low and medium dose mice displayed a significantly lower level of locomotion on PND 120 compared to the controls. Rearing also was changed in BDE-99 groups. On PND 34 in the medium dose group and on PND 60 in the low and medium dose groups mice displayed more rearing than the controls. Tigmotaxis was lower in the medium dose group on PND 60 [29].

To summarize, experiments conducted in mice and rats have shown that exposure to PBDEs during BGS may result in developmental, behavior and learning disorders. A large number of studies on developmental neurotoxic effect of PBDEs show that it does not depend on mouse strain [7,25-29].

\section{Human studies}

In humans, BGS starts during the third trimester of pregnancy and ends around the 2nd year of life [7]. It is suggested that exposure to PBDE during this period affects normal neurodevelopment.

Herbstman et al. [30] investigated prenatal PBDE exposure and child neurodevelopment. Their study population were 329 women who on 11 September 2001 were pregnant and delivered in hospitals placed at most 2 miles from the zero ground (World Trade Center) in New York. Umbilical cord blood was collected at delivery and maternal blood was collected the day after delivery and then the concentrations of BDE-47, 85, 99, 100, 153, 154 and 183 were measured. Furthermore, maternal intelligence was measured using the Test of Non-Verbal Intelligence, Second Edition (TONI-2) and intelligence and development of children at the 12th, 24th and 36th month of age were measured by the use of several tests: the Bayley Scales of Infant Development, Second Edition (BSID-II), the Mental Development Index (MDI) and the Psychomotor Development Index (PDI), and at the 48th and 72nd month 
of age the Wechsler Preschool and Primary Scale of Intelligence, Revised Edition (WPPSI-R) was carried out [30]. Authors found that women who lived closer to the ground zero in New York on September 11 did not have higher blood concentration of PBDEs; however, cord blood concentration of PBDEs depended on time of delivery: women who delivered sooner after September 11 had higher concentration of PBDEs [30].

There was a negative correlation between prenatal BDE-47 exposure and developmental test results in children at the 24th (MDI) and 48th (Full and Verbal IQ scores) month of age. Also BDE-99 was significantly negatively correlated with MDI results in children at the 24th month of age. BDE-100 was negatively correlated with MDI results at the 24th month of age, Full Verbal and Performance IQ scores at the 48th month of age and Performance IQ scores at the 72nd month of age. BDE-153 was negatively correlated with Full and Performance IQ scores at the 48th and 72nd month of age [30].

Children with the lowest developmental scores had the highest cord blood concentration of BDE-47, 99 and 100. It has been suggested that the impact of PBDEs on neurodevelopment may be related to their ability to disturb thyroid hormone homeostasis which is critical for normal brain development [30].

Hoffman et al. [31] investigated the relationship between PBDEs concentration in breast milk and social and emotional development in toddlers. Milk samples were collected 3 months postpartum and concentrations of BDE-28, 47, 99, 100 and 153 were measured. The InfantToddler Social and Emotional Assessment (ITSEA) was completed by mothers when their children were between the 24th and 36th month of age. There were increased externalizing behavior problems in the children, attributable to the higher levels of BDE-47,99 and 100 or the total level of the five congeners. Authors did not observe any other associations between PBDE levels in breast milk and social or emotional developmental domains [31].
Also Gascon et al. [32] suggest an association between PBDE exposure and disturbances in neurodevelopment in human infants. They collected colostrum samples from 209 women to measure concentration of BDE-47, 99, 100, 153, 154, 183 and 209, and children between the 12th-18th month of age were tested for mental and psychomotor development with Bayley Scales of Infant Development. There was a negative association between concentration of total PBDEs in colostrum and the mental test score [32].

Summarizing, exposure to PBDEs during BGS may lead to the impaired neurodevelopment manifested by behavioral disorders and poorer mental and psychomotor development.

\section{REPRODUCTIVE ORGANS AND FERTILITY}

\section{Animal studies}

PBDEs as endocrine disruptors disrupt the endocrine system. Although thyroid hormones are their major target, recent studies in animals have shown that PBDEs interfere with the estrogen- and androgen-mediated processes as well. To examine the impact of PBDEs on fertility and reproductive organs, pregnant rodent dams or dams during lactation have been treated with several PBDEs concentrations. Also pups have been treated with PBDEs to examine their influence on the development of the reproductive organs.

Kuriyama et al. [33] treated pregnant Wistar rats by gavage with 0.06 or $0.3 \mathrm{mg}$ BDE-99/kg (98\% purity) on GD 6. After birth the pups were examined for developmental landmarks (eruption of incisors, fur development, eye opening and testes descent), postnatal reflex (spontaneous cliff-drop aversion reflex and ability to stay on a rotating rod for $3 \mathrm{~min} . \mathrm{s}$ at $7 \mathrm{rpm}$ ), locomotor activity as well as reproductive characteristics (spermatid number, sperm count and morphology, testosterone and luteinizing hormone (LH) levels).

There were no differences between the control group and the PBDEs treated rats in the age concerning fur 
development, testes descent, eye opening and the ability to pass the rotating rod test.

The eruption of incisors and the development of the cliff-drop aversion were delayed in the groups treated with $0.3 \mathrm{mg} / \mathrm{kg}$ b.w. [33].

The $0.3 \mathrm{mg} / \mathrm{kg}$ group on PND 36 was more active during the active phases compared to the controls, and their number of active hours per day was higher. No statistically significant differences were observed on PND 71 [33].

On PND 140 the body weight and organ weight of male offspring were measured. No differences were found in the weight of body, liver and thymus between the control group and the BDE-99 treatment group [33].

There were no differences in absolute testis and epididymis weight, but the $0.3 \mathrm{mg} / \mathrm{kg}$ group had smaller relative testis weight, while relative epididymis weight was smaller in the $0.06 \mathrm{mg} / \mathrm{kg}$ as well as in the $0.3 \mathrm{mg} / \mathrm{kg}$ group [33].

In groups with smaller testis and epididymis weight, sperm and spermatid counts and daily sperm production were also lower. However, daily sperm production was not associated with lower sperm quality. There were also no differences in testosterone and LH levels in the BDE-99 treatment groups compared to the controls [33].

In the BDE-99 exposed groups researchers did not find differences in sexual behavior compared to the control (ejaculatory and mounting latencies, intromission frequency and latency, number of penetrations). However, in the BDE-99 treatment groups the number of animals that had two or more ejaculations during 20 min of mating was significantly lower [33].

Tseng et al. [34] studied the influence of postnatal exposure to BDE-209 (98\% purity) on male mice. They treated young male mice daily by gavage with $10,100,500$ or $1500 \mathrm{mg} / \mathrm{kg}$ b.w. from PND 21 till PND 70. After killing the animals on PND 71, the body and reproductive organs were weighed and sperm motility and motion parameters (curvilinear velocity - VCL, angular progressive velocity - VAP, straight-line velocity - VSL, lateral head amplitude - ALH, beat-cross frequency - BCF) as well as morphology were examined.

In none of the BDE-209 treatment groups, absolute and relative weight of body, testis, epididymis, cauda epididymis and seminal vesicles were significantly different from the controls [34].

Although researchers found a dose-dependent decrease in the VCL, VAP and VLS in the treatment groups, the differences were not significantly different compared to the controls. There were also no significant differences in sperm count, motility and morphology between the groups exposed to BDE-209 and the controls. There were no significant changes in testis DNA in the BDE-209 exposed groups. Also histopathology of testis did not show any differences between treatment groups and the controls [34].

Cecatelli et al. [35] injected subcutaneously pregnant Long Evans rats daily with 1 or $10 \mathrm{mg}$ BDE-99/kg b.w. (>99\% purity) from GD 10 till GD 18. The offspring were divided into two groups and housed without any PBDEs treatment. In the first group, weight and development landmarks such as litter size, survival rate, righting reflex, anogenital distance and eye opening were observed during their growth. When they reached 120 days of age they were sacrificed by decapitation and their ovaries and uterus were removed and weighed. Levels of uterine mRNAs encoding estrogen receptor (ER) alpha, ER beta, progesterone receptor (PR) and insulin-like growth factor-I (IGF-I) were determined by real time PCR [35]. When females from the second group reached 10 weeks of age, they were ovariectomized in general anesthesia which was to reduce endogenous estrogen to low, stable levels. After the surgery they had 2 weeks of recovery and after this they were injected with a single dose of $17 \beta$-estradiol to examine the sensitivity of estrogen target genes to estrogen. Six hours after the injection, the animals were sacrificed by decapitation. Levels of uterine mRNAs encoding ER alpha, ER beta, PR and IGF-I were determined using real time PCR [35]. 
There were no significant differences in developmental landmarks in the BDE-99 treated groups compared to the controls. The body and liver weight of female offspring exposed to BDE-99 determined in diestrus 1 at the 12th week of age were not different from those of the control. Also uterine weight was not changed. Absolute and relative weight of ovaries showed a small but still significant increase in the animals exposed to higher dose of BDE-99 [35].

In group one, in the animals treated with $1 \mathrm{mg} / \mathrm{kg}$, there was an increase of the levels of uterine mRNA encoding IGF-I. In the animals exposed prenatally to $10 \mathrm{mg} / \mathrm{kg}$, uterine mRNA encoding IGF-I was also increased but it was not significantly different from the one in the control. There was a significant dose-dependent decrease in PR mRNA levels in the PBDEs exposed animals. There were no significant differences in ER alpha mRNA levels in the PBDE treated animals compared to those in the control. Developmental exposure to $1 \mathrm{mg} / \mathrm{kg}$ BDE-99 causes an increase of ER beta mRNA in rat uterus. Presence of BDE-99 was detected in blood plasma, adipose tissue and brain [35].

In the second group, mRNA levels of olive oil-injected, ovariectomized offspring served as control for estrogen challenge experiment. In the adult ovariectomized offspring, uterine levels of ER alpha and ER beta did not differ from their levels in the adult intact controls. Levels of PR mRNA and IGF-I mRNA were significantly reduced in the ovariectomized controls compared to the intact control animals [35].

Uterine PR mRNA levels in the ovariectomized animals exposed prenatally to $1 \mathrm{mg} / \mathrm{kg}$ BDE-99 were higher compared to those in the intact adult control animals. There was a dose-dependent increase of IGF-I mRNA in the ovariectomized animals compared to the intact control animals and the animals treated with $10 \mathrm{mg}$ BDE-99/kg, and the difference was significant. ER alpha mRNA were not different from the controls, ER beta mRNA levels were higher in the $10 \mathrm{mg}$ BDE-99/kg group [35].
Talsness et al. [36] treated pregnant Wistar rats by gavage

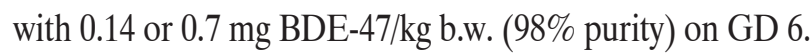
Selected dams were sacrificed 27 days postpartum and their ovaries were weighed and evaluated using light microscopy. Female offspring from F1 generation were killed on PND 38 and their organs were weighed. The second group of females was sacrificed during estrus (PND 100). Their body and organs were weighed and histological examinations of the ovary, uterus, vagina and thyroid were performed. Virgin females from F1 generation at the 22nd week of age were placed with non-exposed males in order to examine fertility.

There was an increase of mean paired ovarian weight in the $0.14 \mathrm{mg} / \mathrm{kg}$ b.w. group in dams sacrificed 27 days postpartum, but the researchers did not detect histological abnormalities in the ovaries in that group. In the $0.7 \mathrm{mg} / \mathrm{kg}$ b.w. group, one female of four exhibited slight follicular dilation indicative of cysts [36].

On PND 38, there were no significant differences in mean body weight in any of the BDE-47 groups. Paired ovarian weight was lower in the $0.14 \mathrm{mg} / \mathrm{kg}$ group and liver weight was reduced in both PBDE groups [36].

Number of follicles was significantly different on PND 38 in the $0.7 \mathrm{mg} / \mathrm{kg}$ b.w. group, and reductions in secondary and tertiary follicles were noted in both BDE-47 groups. In the $0.7 \mathrm{mg} / \mathrm{kg}$ b.w. group, serum estradiol concentrations were lower.

There were no differences in body weight and the weight of reproductive organs on PND 100 [36].

In the thyroid glands, occasional follicular cyst formation in the $0.14 \mathrm{mg} / \mathrm{kg}$ group and mild cyst formation in the $0.7 \mathrm{mg} / \mathrm{kg}$ group took place.

No differences were found in the number of live fetuses, fetal weight and resorption rate in any of the BDE-47 groups compared to the control [36].

Kodavanti et al. [37] treated pregnant Long-Evans rats with 17, 10.2 and $30.6 \mathrm{mg}$ DE-71/kg b.w. (commercial PBDE mixture) from GD 6 to PND21 except for the day 
of birth (PND 0). Eight pups from each litter were used for further studies, i.e. males for neurobehavioral testing, females for motor activity and mammary gland development. There were no abnormalities in maternal body weight. Exposure to DE-71 did not cause disturbances in the hormonal pattern of maternal body weight. Also body weight of pups did not deviate from that of the control [37].

Authors did not find significant differences in the anogenital distance (AGD) of the male offspring compared to the controls in any of the DE-71 dose groups [37].

In the group exposed to $30.6 \mathrm{mg} \mathrm{DE}-71 / \mathrm{kg}$ b.w. from pregnancy till PND 21, the age of preputial separation (PPS) was significantly delayed compared to the control males. There was no significant effect in mammary gland development on PND 4 at any of DE-71 doses. However, on PND 21 in the 10.2 and $30.6 \mathrm{mg} / \mathrm{kg}$ b.w. groups, there were significant differences in mammary glands compared to the controls: lack of outgrowth, fewer lateral branches and limited terminal end bud [37].

To summarize, PBDEs given during gestation and/or postnatally can cause reproductive effects. In mice and rats exposed prenatally to BDE-47, BDE-99 and DE-71 there were changes in absolute and relative weight of ovaries [35,36], relative weight of testis and epididymis [33], sperm and spermatoid production [33]. BDE-209 postnatal exposure of male mice caused changes in sperm motility and motion such as VCL, VAP and VLS [34].

\section{Human studies}

Harley et al. [38] searched for the relationship between PBDE serum concentration and reduced fertility among 223 young Mexican-immigrant women in the United States. BDE-47, 99, 100 and 153 were detected in more than $97 \%$ of women and these congeners were highly correlated. These four congeners and their total concentrations were associated with reduced fertility in the group of women who were actively trying to get pregnant $(\mathrm{N}=107)$.
Meeker et al. [39] investigated the relationship between PBDE concentration in house dust and hormone levels in men. Participants were between 18 and 54 years of age and men from infertile couples were included (due to male factor, a female factor or combination of both). Dust samples were collected from the used household vacuum bags and concentrations of BDE-47, 99 and 100 were measured. Levels of: testosterone, sex hormone binding globulin (SHBG), inhibin B, luteinizing hormone (LH), follicle stimulating hormone (FSH), estradiol, prolactin, FT4, T3 and thyrotropin (TSH) were measured in blood samples. Free androgen index (FAI) was calculated in terms of molar ratio of total testosterone to SHBG [39]. A positive association between $\mathrm{PBDE}$ dust concentrations and serum concentration of SHBG, inhibin B and FT4 was found. All three congeners were inversely associated with FSH and LH serum concentration. BDE-47 and BDE-99 were in inverse relationship with FAI. There were no associations observed between PBDEs and T3 or TSH [39]. Meijer et al. [40] investigated the influence of prenatal exposure to selected PBDEs on infant sexual development. Concentrations of BDE-47,99, 100,153 and BDE-154 in maternal serum were measured, and in serum of infants of 3 months, levels of inhibin B, sex hormone bonding globulin (SHBG), testosterone, free testosterone, luteinizing hormone, follicle stimulating hormone (FSH) estradiol and free estradiol were determined. Also testes volume and penile length were measured in boys at the 3rd and 18th month of age.

There was a positive association between maternal serum concentration of BDE-154 and testosterone and SHBG levels in boys of 18 months of age. Also testes volume and penile length were positively associated with maternal BDE-154 serum concentration [40].

Akutsu et al. [41] examined the relationship between human serum PBDEs levels and sperm quality. The concentration of 29 PBDE congeners in men serum samples was analyzed. Sperm quality was analyzed in accordance with WHO criteria. 
Mainly four congeners, BDE-47, BDE-99, BDE-100 and BDE-153 were detected in male serum samples. A significant positive correlation was found to occur between the concentration of BDE-47 and BDE-99, BDE-47 and BDE-100, BDE-99 and BDE-100 but no correlation was found between BDE-153 and any of the three other congeners [41].

Every participant had a sperm concentration between 25-115 million/ml. There was a strong inverse correlation between the serum BDE-153 concentration, sperm concentration and testis size but no correlation was found between sperm concentration, testis size and any of the other congeners [41].

Authors suggest that because PBDEs are endocrine disruptors with thyroid hormonal and sex hormonal activities, they might have a negative impact on male fertility [41].

Previous studies have shown that exposure to PBDEs may lead to fertility disorders. BDE-47, 99 and 100 may cause disorders in sex hormone concentration [39], BDE-153 may affect testes volume and sperm concentration [41], while high serum concentration of BDE-154 may affect penile length, testosterone and SHBG concentration and testes volume [40].

The number of papers in the literature regarding the influence of PBDEs on human body is clearly smaller than that of the reports on animal testing. The results of previous studies and animal experiments can be used to formulate the first, cautious conclusions whether and how PBDEs affect our health.

\section{SUMMARY}

The studies in animals and humans have shown that exposure to PBDEs may lead to disorders in thyroid hormone system, neurodevelopment, fertility and reproductive organs. In rodents, pre- and postnatal exposure to BDE-209 caused reduction in total serum T4 [17] and T3 [13]. In rats treated with BDE-99, T4, FT4 and T3 serum levels were lower [12], while the rats exposed prenatally to BDE-47 showed lower concentrations of T3, FT3 and TSH [15]. It is suggested that in humans PBDEs may have hyperthyroid effect [18]. It means that exposure to PBDEs may lead to subclinical hyperthyroidism which can cause serious long-term consequences [20,21].

Rodents and humans exposed to PBDEs during BGS showed signs of disturbed neurodevelopment. The mice treated with BDE-47, 99, 183, 203 and 209 showed differences in spontaneous behavior compared to the controls [25-28]. In humans, a negative association between number of scores reached by children in Bayley Scales Development test and concentration of PBDEs in colostrum [32] was found. While an increase of externalizing behavior problems in children was associated with higher levels of PBDEs in breast milk [31]. Also Herbstman et al. [30] observed that higher cord blood concentration of PBDEs is associated with lower number of scores reached by children in developmental tests. It is hypothesized that PBDEs may have impact on neurodevelopment in mammals because of their ability to disturb thyroid hormone homeostasis which is critical for normal brain development [30].

In reproductive system, exposure of rodents to PBDEs caused changes in reproductive organs weight and in sperm properties [33,35,36]. Harley et al. [38] found an association between reduced fertility among women actively trying to get pregnant and serum concentration of PBDEs. The authors suggest that there are two mechanisms by which PBDEs might affect fertility: hypothalamic-pituitary-thyroid axis and hypothalamic-pituitary-gonadal axis [38]. In men, exposure to PBDEs may lead to changes in concentrations of sex hormones [39], sperm concentration and testis size [41]. Also sexual development of infants may be disturbed by prenatal exposure to PBDEs [40]. Previous studies on PBDEs have shown that besides their advantages these compounds also have many disadvantages. On the one hand, they protect people from the destructive force of fire but on the other, they have a negative impact on our health. They disturb function of thyroid hormone system 
which is essential for proper development of nervous and reproductive systems as well as for their correct functioning. It is necessary to conduct further reliable research to assess the magnitude of the damages which PBDEs can cause in human body. We may soon be forced to decide whether harmful effects of PBDEs to human health do not exceed the benefits of their flame-retarding properties.

\section{REFERENCES}

1. Bromine Science and Environmental Forum (BSEF). European regulation and brominated flame retardants [cited 2012 Oct 9]. Available from: http://www.bsef.com. http://www.bsef. com/regulation/europe/an-overview-of-european-legislation

2. European Food Safety Authority (EFSA). Scientific Opinion on Polybrominated Diphenyl Ethers (PBDEs) in Food. Parma, Italy 2011 [cited 2012 Oct 7]. Available from: http:// www.efsa.europa.eu. http:/www.efsa.europa.eu/en/efsajournal/doc/2156.pdf

3. Talsness C.E.: Overview of toxicological aspects of polybrominated diphenyl ethers: A flame-retardant additive in several consumer products. Environ Res. 2008;108:158-67.

4. Directive 2003/11/EC of the European Parliament and of the Council of 6 February 2003 amending for the 24th time Council Directive 76/769/EEC relating to restrictions on the marketing and use of certain dangerous substances and preparations (pentabromodiphenyl ether, octabromodiphenyl ether).

5. Stockholm Convention on Persistent Organic Pollutants, Stockholm, 22 May 2001. Changes in 2010-New Substances.

6. De Wit CA. An overview of brominated flame retardants in the environment. Chemosphere. 2002;46:583-624, http://dox. doi.org10.1016/S0045-6535(01)00225-9.

7. Viberg H, Fredriksson A, Jakobsson E, Orn U, Eriksson P. Neurobehavioral derangements in adult mice receiving decabrominated diphenyl ether (PBDE 209) during a defined period of neonatal brain development. Toxicol Sci. 2003;76:11220, http://dx.doi.org/10.1093/toxsci/kfg210.
8. Branchi I, Capone F, Alleva E, Costa LG. Polybrominated diphenyl ethers: Neurobehavioral effects following developmental exposure. Neurotoxicology. 2003;24:449-62, http:// dx.doi.org/10.1016/S0161-813X(03)00020-2.

9. Czerska M, Kamińska J, Zieliński M, Ligocka D. [Polybrominated diphenyl ethers: sources of exposure and expected health effects]. Med Pr. 2012;63(4):463-9. Polish.

10. Crisp TM, Clegg ED, Cooper RL, Wood WP, Anderson DG, Baetcke KP et al. Environmental endocrine disruption: An effects assessment and analysis. Environ Health Perspect. 1998;106:11-56, http://dx.doi.org/10.2307/3433911.

11. Santisteban P, Bernal J. Thyroid development and effect on the nervous system. Rev Endocr Metab Disord. 2005;6: 217-28, http://dx.doi.org/10.1007/s11154-005-3053-9.

12. Kuriyama S, Wanner A, Fidalgo-Neto A, Talsness CH, Koerner W, Chahoud I. Developmental exposure to low dose PBDE-99: Tissue distribution and thyroid hormone levels. Toxicology. 2007;242:80-90, http://dx.doi.org/10.1016/ j.tox.2007.09.011.

13. Tseng LH, Li MH, Tsai SS, Lee CW, Pan MH, Yao WJ, et al. Developmental exposure to decabromodiphenyl ether (PBDE 209): Effects on thyroid hormone and hepatic enzyme activity in male mouse offspring. Chemosphere. 2008;70: 640-7, http://dx.doi.org/10.1016/j.chemosphere.2007.06.078.

14. Hallgren S, Darnerud PO. Effects of polybrominated diphenyl ethers (PBDEs), polychlorinated biphenyls (PCBs) and chlorinated paraffins (CPs) on thyroid hormone levels and enzyme activities in rats. Organohal Compounds. 1998;35:391-4.

15. Andrade AJM, Kuriyama SN, Akkoc Z, Talsness CE, Chahoud I. Effects of developmental low dose PBDE 47 exposure on thyroid hormone status and serum concentrations of FSH and inhibin B in male rats. Organohal Compounds. 2004;66:3858-63.

16. Darnerud PO, Sinjari T. Effects of polybrominated diphenyl ethers (PBDEs) and polychlorinated biphenyls (PCBs) on thyroxine and TSH blood levels in rats and mice. Organohal Compounds. 1996;29:316-9. 
17. Rice DC, Reeve EA, Herlihy A, Zoeller RT, Thompson WD, Markowski VP. Developmental delays and locomotor activity in the C57BL6/J mouse following neonatal exposure to the fully-brominated PBDE, decabromodiphenyl ether. Neurotoxicol Teratol. 2007;29:511-20, http://dx.doi.org/10.1016/ j.ntt.2007.03.061.

18. Chevrier J, Harley KG, Bradman A, Gharbi M, Sjödin A, Eskenazi B. Polybrominated diphenyl ether (PBDE) flame retardants and thyroid hormone during pregnancy. Environ Health Perpect. 2010;118:1444-9, http://dx.doi.org/10.1289/ ehp.1001905.

19. Casey BM, Dashe JS, Wells CE, McIntire DD, Leveno KJ, Cunningham FG. Subclinical hyperthyroidism and pregnancy outcomes. Obstet Gynecol. 2006;107:337-41, http:// dx.doi.org/10.1097/01.AOG.0000197991.64246.9a.

20. Marqusee E, Haden ST, Utiger RD. Subclinical thyrotoxicosis. Endocrinol Metab Clin North Am. 1998;27:37-49, http:// dx.doi.org/10.1016/S0889-8529(05)70296-6.

21. Papi G, Pearce EN, Braverman LE, Betterle C, Roti E. A clinical and therapeutic approach to thyrotoxicosis with thyroid-stimulating hormone suppression only. Am J Med. 2005;118:349-61, http://dx.doi.org/10.1016/j.amjmed.2005.01.004.

22. Lin DY, Chao HR, Wang SL, Päpke O. Associations between PCDD/Fs, PCBs, OCPs and PBDEs in breast milk and thyroid, growth, and steroid sex hormones. Organohal Compounds. 2009;71:547-50.

23. Davison AN, Dobbing L. Applied neurochemistry. Oxford: Blackwell; 1968.

24. Campbell BA, Lytle LD, Fibiger HC. Ontogeny of adrenergic arousal and cholinergic inhibitory mechanisms in the rat. Science. 1969:166:635-7.

25. Eriksson P, Jakobsson E, Fredriksson A. Brominated flame retardants: A novel class of developmental neurotoxicants in our environment? Environ Health Perspect. 2001;109: 903-90, http://dx.doi.org/10.1289/ehp.01109903.

26. Eriksson P, Viberg H, Jakobsson E, Fredriksson A. A brominated flame retardant, 2,2',4,4'5-pentabromodiphenyl ether: Uptake, retention and induction of neurobehavioral alterations in mice during a critical phase of neonatal brain development. Toxicol Sci. 2002;67:98-103, http://dx.doi. org/10.1093/toxsci/67.1.98.

27. Viberg H, Johansson N, Fredriksson A, Eriksson J, Marsh G, Eriksson P. Neonatal exposure to higher brominated diphenyl ethers, hepta-, octa-, or nonabromodiphenyl ether, impairs spontaneous behavior and learning and memory functions of adult mice. Toxicol Sci. 2006;92:211-8, http://dx.doi. org/10.1093/toxsci/kfj196.

28. Viberg H, Fredriksson A, Eriksson P. Investigations of strain and/or gender differences in developmental neurotoxic effects of polybrominated diphenyl ethers in mice. Toxicol Sci. 2004;81:344-53, http://dx.doi.org/10.1093/toxsci/kfh215.

29. Branchi I, Alleva E, Costa LG. Effects of perinatal exposure to a polybrominated diphenyl ether (PBDE 99) on mouse neurobehavioral development. Neurotoxicology. 2002;23:375-84, http://dx.doi.org/10.1016/S0161-813X(02)00078-5.

30. Herbstman JB, Sjödin A, Kurzon M, Lederman SA, Jones RS, Rauch V, et al. Prenatal exposure to PBDEs and neurodevelopment. Environ Health Perspect. 2010;118: 712-9, http://dx.doi.org/10.1289/ehp.0901340.

31. Hoffman K, Adgent M, Goldman B, Sjödin A, Daniels J. Lactational exposure to polybrominated diphenyl ethers and its relation to social and emotional development among toddlers. Environ Health Perspect. 2012;120:1438-42, http:// dx.doi.org/10.1289/ehp.1205100.

32. Gascon M, Fort M, Matrinez D, Carsin AE, Forns J, Grimalt JO, et al. Polybrominated diphenyl ethers (PBDEs) in breast milk and neuropsychological development in infants. Environ Health Perspect. 2012;120:1760-5, http://dx.doi. org/10.1289/ehp.1205266.

33. Kuriyama SN, Talsness CE, Grote K, Chahoud I. Developmental exposure to low-dose PBDE-99: Effects on male fertility and neurobehavior in rat offspring. Environ Health Perspect. 2005;113:149-54, http://dx.doi.org/10.1289/ehp.7421.

34. Tseng LH, Lee CW, Pan MH, Tsai SS, Li MH, Chen JR, et al. Postnatal exposure of male mouse 
to $2,2^{\prime}, 3,3^{\prime}, 4,4^{\prime}, 5,5,6,6,6^{\prime}$-decabrominated diphenyl ether: Decreased epididymal sperm functions without alterations in DNA content and histology in testis. Toxicology. 2006;224:33-43, http://dx.doi.org/10.1016/j.tox.2006. 04.003 .

35. Ceccatelli R, Faass O, Schlumpf M, Lichtensteiger W. Gene expression and estrogen sensitivity in rat uterus after developmental exposure to the polybrominated diphenylethers PBDE 99 and PCB. Toxicology. 2006;220:104-16, http://dx.doi.org/10.1016/j.tox.2005.12.004.

36. Talsness CE, Kuriyama SN, Sterner-Kock A, Schnitker P, Grande SW, Shakibaei M, et al. In utero and lactational exposure to low doses of polybrominated diphenyl ether-47 alter the reproductive system and thyroid gland of female rat offspring. Environ Health Perspect. 2008;116:308-14. doi 10.1289/ehp.10536.

37. Kodavanti PRS, Coburn C, Moser V, Mac Phail RC, Fenton SE, Stroker T, et al. Developmental exposure to a commercial PBDE mixture, DE-71: neurobehavioral, hormonal, and reproductive effects. Toxicol Sci. 2010;116:2970312, http://dx.doi.org/10.1093/toxsci/kfq105.

38. Harley KG, Marks AR, Chevrier J, Bradman A, Sjödin A, Eskenazi B. PBDE concentrations in women's serum and fecundability. Environ Health Perspect. 2010;118:699-704, http://dx.doi.org/10.1289/ehp.0901450.

39. Meeker JD, Johnson PI, Camann D, Hauser R. Polybrominated diphenyl ether (PBDE) concentrations in house dust are related to hormone levels in men. Sci Total Environ. 2009;497:3425-9, http://dx.doi.org/10.1016/j.scitotenv.2009. 01.030 .

40. Meijer L, Brouwer B, De Jong FHJ, Bergman A, Sauer PJJ. Influence of prenatal exposure to selected organohalogans on infant sexual and neurological development. Organohal Compounds. 2008;70:658-61.

41. Akutsu K, Takatori S, Nozawa S, Yoshiike M, Nakazawa H, Hayakawa K, et al. Polybrominated diphenyl ethers in human serum and sperm quality. Bull Environ Contam Toxicol. 2008;80: 345-50, http://dx.doi.org/10.1007/s00128-008-9370-4.

This work is available in Open Access model and licensed under a Creative Commons Attribution-NonCommercial 3.0 Poland License - http://creativecommons.org/ licenses/by-nc/3.0/pl/deed.en. 